\title{
Call for Papers
}

\section{"Followercentric Approaches to Leadership"}

\section{A Topical Issue of the Zeitschrift für Psychologie / Journal of Psychology}

\author{
Guest Editors: Michelle C. Bligh (Claremont Graduate University, CA, USA) and \\ Jeffrey C. Kohles (Center for Leadership Innovation and Mentorship Building \\ (CLIMB), California State University San Marcos, CA, USA)
}

Over the past several decades, scholars have focused increased attention on followers' needs, motivations, and attributions as critical aspects of the leadership relationship. These findings suggest that, just as not all leaders are the same, followers vary, sometimes dramatically, in their needs for certain types of leaders and leadership (e.g., toxic, authoritarian, charismatic, authentic, paternalistic, servant) as well as their susceptibility and responsiveness to certain types of leadership (authentic, transformational, dictatorial, directive vs. participative, etc.). For this topical issue, we invite contributions that may include one or more of the following:

1. followers' characteristics and potential biases that influence attributions of leadership, including attributions for organizational success and failure and the "Romance of Leadership";

2. the role of followers' characteristics, perceptions, and motivations in interpreting leadership ratings, as well as the potential impact of situational factors such as the role of crisis and follower uncertainty or fear on these processes; and

3. the social construction of leadership, including social contagion processes and other interfollower processes.

The focus of this topical issue of the Zeitschrift für Psychologie / Journal of Psychology on "Followercentric Approaches to Leadership" is not limited to the topics listed, but seeks to encompass a broad view of what a focus on followers brings to the study of leadership; the goal of this topical issue is to bring together a set of papers that represent new directions in leadership that stem from the examination of followers and followership. We are looking for original empirical articles that advance knowledge concerning one or more of these topics, as well as review-type articles that focus on the interpretation of existing trends in followercentric approaches and where we should go from here.
The topical issue invites submissions of empirical, theoretical, and review papers. Please submit contributions electronically to:

Michelle C. Bligh (michelle.bligh@cgu.edu)

For additional information, please contact Michelle C. Bligh (michelle.bligh@cgu.edu) or Jeffrey C. Kohles (jkohles@csusm.edu)

There is a two-stage submissions process. Initially, authors are requested to submit only abstracts of their proposed papers. Authors requested to submit full papers should then do so. All papers will undergo full peer review.

\section{Deadline for submission of abstracts is October 15, 2011. \\ Deadline for submission of full papers is February 15, 2012.}

The journal seeks to maintain a short turnaround time, with the final version of the accepted papers being due by May 15,2012 . The topical issue will be published in autumn 2012.

The Zeitschrift für Psychologie / Journal of Psychology was founded in 1890 and is the second oldest psychology journal in the world. One of the founding editors was Hermann Ebbinghaus. Since 2007, it is published in English and devoted to topical issues that provide state-of-the-art overviews of current research in psychology.

\section{Guidelines for Article Preparation}

For detailed author guidelines, please see the journal's website at www.hogrefe.com/journals/zfp. 